\title{
Structural Characterization and Dielectric Properties of the Effect of Carbon Nanotubes and Silicon on AA2024 Metal Matrix Composites
}

\author{
Muniyappan Mani \\ Thiruvalluvar Government Arts College \\ lyandurai Natesan ( $\square$ ayandurai15@gmail.com ) \\ Periyar University https://orcid.org/0000-0002-7796-011X
}

\section{Research Article}

Keywords: AA 2024 Composites, Carbon Nanotubes, Silicon, Dielectric properties

Posted Date: February 26th, 2021

DOI: https://doi.org/10.21203/rs.3.rs-246810/v1

License: (-) This work is licensed under a Creative Commons Attribution 4.0 International License. Read Full License 


\section{Abstract}

This research work focus on the formation of AA2024-carbon nanotubes-silicon hybrid metal matrixcomposites. Structure morphology, structural characterization, elemental identification and dielectric properties of AA 2024 in the presence of carbon nanotubes, silicon andits combinations at various proportions was evaluated using SEM, XRD, EDX and Hioki 3532-50 LCR Hi-Tester. A two-stage stir casting method was used for the fabrication of AA2024 hybrid metal matrix composites. It was observed that the size of the AA $2024+$ $4 \%$ CNT $+2 \%$ Si composite wasfound to be $23.6 \mathrm{~nm}$, this shows enhanced results than other composites prepared. Dielectric properties of composites were characterized as a function of composition and frequency. It was found that the dielectric constant, dielectric loss and dissipation factor decreases smoothly with an increase of reinforcements and also frequency.

\section{Introduction}

MMCs filled with nanoparticles are proficient materials, appropriate for an entire host purpose. These composites contain metal as a matrix crammed with nanoparticles marking many properties extremely dissimilar from those of the base material. The nanoparticles can advance the base material in terms of physical, chemical and mechanical properties [1].

Aluminium / Aluminium 2024 alloy has a high strength to weight ratio and excellent fatigue resistance. Because of this, Aluminium/Aluminium 2024 alloy is extensively employed in the aircraft industry. Tribological properties are the main drawbacks of the composites. For this reason, the engineering society has got to build up a totally unique material with superior tribological properties [25].

The discovery of carbon nanotubes (CNT) opened new perspectives for the event of composite materials. Carbon nanotubes have outstanding properties [6] and that they have been involved within the fabrication of composites as reinforcements. CNTs have a rarity and outstanding electrical and mechanical properties [7]. Additionally to good chemical and thermal stability, CNT demonstrates high yield strength and modulus of elasticity values [8].

Silicon (Si) is the most copious electropositive element within the Earth's crust. It is a metalloid with an evident metallic luster and extremely brittle. Pure silicon is termed as an intrinsic semiconductor, although the concentration of its semiconduction is highly increased by adding a tiny low amount of impurities. Silicon produces different series of hydrides, different halides and plenty of series of oxygen-containing compounds. Silicon is additionally a major element of some steels and also the main element in bricks. Elemental silicon gives more resistance to materials like aluminium, magnesium and copper [9].

Analysis of dielectric property ends up in the state changes from initial unspoiled condition to the ultimate breakdown condition due to the application of an assorted applied field. Dielectric properties are generally used for identifying the strongest and weakest nature of the material prior to the applying load. Dielectric properties could even be wont to portray mechanical properties like strength, life, and sturdiness of the material [10].

The present work has been focused on the fabrication of hybrid metal matrix composites by the utilization of carbon nanotubes and silicon into the AA 2024 matrix by stir casting method [11]. The prepared composites were subjected to structural, elemental, and dielectric properties analysis.

\section{Materials And Methods}

\subsection{Materials}

AA 2024 was obtained from Plus metals, Mumbai, India. Carbon Nanotubes (CNTs) were purchased from IENT Inc, Erode, TamilNadu, India. Silicon (Si) was purchased from Coimbatore Metals, Coimbatore, TamilNadu, India.

\subsection{Method of preparing composites}

High energy ball milling was used for the synthesis of silicon nanoparticles [12] and stir casting unit was used for the synthesis of composite materials.

In this work, AA2024-CNT, AA2024-silicon, AA2024-CNT-silicon at various proportions was prepared. Pure AA 2024 was melted up to $750 \mathrm{C}$ and the molten material was stirred between 10 to $15 \mathrm{~min}$ at an impeller speed of $325 \mathrm{rpm}$. At this stage, carbon nanotubes, 
silicon and their mixtures are added. The carbon nanotubes and silicon nanoparticles and their various proportions were heated up to $300 \mathrm{C}$ for 3 hours to require away the dampness. The resultant composite material was transferred into the eternal metallic pattern. The liquid material was allowed to solidify within the pattern.

\subsection{Method of Preparing Composites for SEM, EDX, XRD and dielectric studies}

The composites produced were examined by using SEM, EDX, XRD and also dielectric studies. A piece of composite material of $1 \mathrm{~cm}^{2}$ area and $2 \mathrm{~mm}$ thickness (Fig. 1) is used for SEM and EDX, $2 \mathrm{~cm}$ length $1 \mathrm{~cm}$ width and $2 \mathrm{~mm}$ thickness (Fig. 2) is used for XRD and 1 $\mathrm{cm}^{2}$ area and $1.5 \mathrm{~mm}$ thickness (Fig 3) was used for the dielectric properties. The sample is belt grinded, polished with emery papers and washed out, these samples are shown in Fig. 1, Fig. 2 and Fig. 3.

\subsection{Scanning Electron Microscope and EDX analysis}

SEM gives thorough high-resolution images of the samples. This can be done by scanning a focused electron beam across the surface of the samples and also detecting the secondary electron beam. Quantitative elemental information of the prepared samples was identified with the help of an Energy Dispersive X-Ray Analyzer (EDX). JEOL Model JSM-6390 LV scanning electron microscope (SEM) equipped with an energy dispersive X-ray (EDX) detector of the Oxford data reference system was used in this study.

\subsection{X-Ray Diffraction Analysis}

XRD pattern was recorded using Shimadzu XRD-6000 X-ray diffractometer that uses Cu Ka radiation $(\lambda=0.15406 \mathrm{~nm})$ in the scan range $2 \theta=10^{\circ}$ to $90^{\circ}$. Shimadzu X'pert pro software was used to for the data collection. The peaks of the X-ray diffraction pattern observed are compared with the available standard JCPDS data to support the crystal structure.

\subsection{Observation of dielectric property}

Dielectric constant, dielectric loss and dissipation factor for the prepared samples were characterized as a function of reinforcements and frequency employing a Hioki 3532-50 LCR Hi-Tester. Hioki 3532-50 LCR Hi-Tester uses a touch panel as the user interface. Examination frequency at high resolution can be set from $42 \mathrm{~Hz}$ to $5 \mathrm{MHz}$. Impedance |Z|, phase angle $\theta, \mathrm{L}, \mathrm{C}$, and R, etc., (merely fourteen parameters) can be simultaneously displayed on the screen [13].

Akhter et. al., [14] estimated the real part of the dielectric constant $\left(\varepsilon^{\prime}\right)$ and also dielectric loss $(\varepsilon ")$, using the relation, see formula 1 in the supplementary files.

\section{Results And Discussion}

\subsection{Inferences of microstructural characterization}

SEM images (Fig. 4 \& Fig. 5) were recorded for carbon nanotubes and silicon. It shows that the carbon nanotubes have a smooth surface with bundles of tangled tubes [15]. The silicon has an irregular particle structure and a rough texture [16].

SEM images (Fig. 6 a-i) of AA 2024, AA $2024+2 \%$ CNT, AA 2024 + 4\% CNT, AA $2024+2 \%$ Si, AA $2024+4 \%$ Si, AA $2024+2 \%$ CNT + 2\% $\mathrm{Si}, \mathrm{AA} 2024+2 \% \mathrm{CNT}+4 \% \mathrm{Si}, \mathrm{AA} 2024+4 \% \mathrm{CNT}+2 \%$ Si and AA $2024+4 \%$ CNT + 4\% Si shows that reinforcement particles are distributed evenly throughout the specimen. The clustering of the reinforcement particles was not seen in the composites. Hence the two-step stir casting method helps in attaining the uniform distribution of reinforcement particles in the AA 2024 matrix.

\subsection{EDX Analysis}

EDX spectra of the prepared samples are shown in Fig. 7 a-k and the results are summarized in table 1. Here, aluminium was found to be $91.96 \%$, which is the major element in AA2024. In addition to that, copper (4.5\%) and magnesium (1.64\%) indicates that these elements play a significant role with aluminium to form an alloy. Manganese, iron, silicon, chromium and zinc were observed in the EDX spectrum of AA 2024, which are also supporting elements to form the AA2024 alloy. So, apart from aluminium other elements found in AA2024 are played some of the major roles in the formation of alloy.

Table 1 EDX elemental identification for AA 2024 HMMCs 


\begin{tabular}{|llllllllllll|}
\hline Element & $\begin{array}{l}\text { AA2024 } \\
(\%)\end{array}$ & $\begin{array}{l}\mathrm{CNT} \\
(\%)\end{array}$ & $\begin{array}{l}\mathrm{Si} \\
(\%)\end{array}$ & $\begin{array}{l}\text { AA2024 } \\
+\end{array}$ & $\begin{array}{l}\text { AA2024 } \\
+\end{array}$ & $\begin{array}{l}\text { AA2024 } \\
+\end{array}$ & $\begin{array}{l}\text { AA2024 } \\
+\end{array}$ & $\begin{array}{l}\text { AA2024 } \\
+2 \% \mathrm{CNT}\end{array}$ & $\begin{array}{l}\text { AA2024 } \\
+2 \% \mathrm{CNT}\end{array}$ & $\begin{array}{l}\text { AA2024 } \\
+4 \% \mathrm{CNT}\end{array}$ & $\begin{array}{l}\text { AA2024 } \\
+4 \% \mathrm{CNT}\end{array}$ \\
$\mathrm{Al}$ & 91.96 & 1.72 & - & 88.66 & 86.74 & 89.25 & 86.82 & 86.14 & 84.85 & 83.72 & 81.80 \\
$\mathrm{C}$ & - & 75.40 & - & 1.94 & 3.95 & - & - & 1.96 & 1.98 & 3.98 & 3.97 \\
\hline $\mathrm{Si}$ & 0.49 & - & 73.19 & 0.47 & 0.41 & 2.45 & 4.47 & 2.41 & 4.38 & 2.43 & 4.32 \\
\hline $\mathrm{O}$ & - & 22.88 & 26.81 & 2.87 & 2.13 & 2.08 & 2.09 & 2.14 & 2.73 & 1.58 & 2.41 \\
\hline $\mathrm{Mg}$ & 1.64 & - & - & 1.22 & 1.18 & 1.25 & 1.27 & 1.15 & 1.23 & 1.27 & 1.18 \\
\hline $\mathrm{Mn}$ & 0.68 & - & - & 0.51 & 0.47 & 0.46 & 0.48 & 0.51 & 0.45 & 0.47 & 0.49 \\
\hline $\mathrm{Fe}$ & 0.43 & - & - & 0.67 & 1.46 & 0.92 & 0.89 & 1.98 & 1.14 & 2.07 & 2.18 \\
\hline $\mathrm{Cu}$ & 4.5 & - & - & 3.58 & 3.58 & 3.59 & 3.98 & 3.43 & 3.24 & 4.48 & 3.65 \\
\hline $\mathrm{Cr}$ & 0.09 & - & - & 0.08 & 0.08 & - & - & 0.08 & - & - & - \\
\hline $\mathrm{Zn}$ & 0.21 & - & - & - & - & - & - & 0.20 & - & - & - \\
\hline
\end{tabular}

\subsection{X-ray Diffraction (XRD)}

The X-ray diffraction (XRD) analysis is employed to substantiate the structure of the materials which is obtained from used elements in the form of the prepared alloy composite samples. The consolidated results of XRD spectra for all samples are shown in Fig. 8 and the results are summarized in Table 2. The peaks were compared with the standard diffraction data to analyse the presence of various phases present in the composite materials.

Table 2 X-ray diffraction data

\begin{tabular}{|lllllll|}
\hline S. No & Element & 2 Theta(deg) & Hkl & Cell Parameters & Structure & JCPDS No \\
\hline 1 & Al & 38.6 & 111 & $\mathrm{a}=\mathrm{b}=\mathrm{c}=4.049$ & Cubic & $04-0787$ \\
\hline 2 & $\mathrm{Cu}$ & 44.6 & 111 & $\mathrm{a}=\mathrm{b}=\mathrm{c}=3.615$ & Cubic & $04-0836$ \\
\hline 3 & $\mathrm{Mn}$ & 64.8 & 331 & $\mathrm{a}=\mathrm{b}=\mathrm{c}=6.30$ & Cubic & $89-4086$ \\
\hline 4 & $\mathrm{Mg}$ & 78.4 & 202 & $\mathrm{a}=\mathrm{b}=3.208, \mathrm{c}=5.209$ & Hexagonal & $89-5003$ \\
\hline 5 & $\mathrm{Fe}$ & 82.6 & 211 & $\mathrm{a}=\mathrm{b}=\mathrm{c}=2.866$ & Cubic & $87-0721$ \\
\hline 6 & $\mathrm{Zn}$ & 35.5 & 002 & $\mathrm{a}=\mathrm{b}=2.665, \mathrm{c}=4.947$ & Hexagonal & $87-0713$ \\
\hline 7 & $\mathrm{Cr}$ & 40.6 & 002 & $\mathrm{a}=\mathrm{b}=2.722, \mathrm{c}=4.434$ & Hexagonal & $89-2871$ \\
\hline 8 & $\mathrm{Si}$ & $28.6,47.6$ & 111,220 & $\mathrm{a}=\mathrm{b}=\mathrm{c}=5.392$ & Cubic & $80-0018$ \\
\hline 9 & $\mathrm{CNT}$ & $26.1,43.8$ & 002,101 & $\mathrm{a}=\mathrm{b}=2.470, \mathrm{c}=6.724$ & Hexagonal & $41-1487$ \\
\hline
\end{tabular}

The diffraction peak ( $2 \theta)$ observed at $38.6^{\circ}$ is corresponding to $\left(\begin{array}{lll}1 & 1 & 1\end{array}\right)$ plane of aluminium (Al) cubic phase which is matched with the standard value (JCPDS file No. 04-0787). This observation confirms the presence of aluminium as indicated by Giancarlo Richard Salazar-Banda et. al., (2013) [17], Sourabh Biswas et. al., (2017) [18] and M. Senthil Kumar et. al., (2019) [19]. The diffraction peak observed at $44.6^{\circ}$ corresponding to $\left(\begin{array}{lll}1 & 1 & 1\end{array}\right)$ plane of copper $(\mathrm{Cu})$ cubic phase and matched with the standard values (JCPDS file No. 040836). This observation confirms the presence of copper as indicated by T. Theivasanthi et. al., (2010) [20]. $2 \theta$ reflection at $64.8^{\circ}$ corresponding to (3 3 1) plane of manganese (Mn) cubic phase and matched with the standard values (JCPDS file No. 89-4086). This is often confirmed by Alain Manceau et. al., (1992) [21]. The diffraction peak value of $2 \theta$ observed at $78.4^{\circ}$ corresponding to (2 02$)$ plane of magnesium (Mg) hexagonal phase and matched with the standard value (JCPDS file No. 89-5003) which is compared with the previously observed XRD pattern of magnesium. This is confirmed with the previous reports observed by Sumiaki Nakano et. al., (2004) [22]. The diffraction peak observed at $82.6^{\circ}$ corresponding to $\left(\begin{array}{lll}2 & 1 & 1\end{array}\right)$ plane of iron ( $\mathrm{Fe}$ ) cubic phase and matched with the standard value (JCPDS file No. 87-0721) and this is reported by Yoshiaki Hirano et. al., (2016) [23]. $2 \theta$ reflection observed at $35.5^{\circ}$ corresponding 
to $\left(\begin{array}{ll}0 & 0\end{array}\right)$ plane of zinc $(\mathrm{Zn})$ hexagonal phase and matched with the standard value (JCPDS file No. 87-0713) which is compared with the previous reports of Dang Le Tri Nguyen et. al., (2017) [24], Chia-Hao Lu et. al., (2014) [25] and Ashok Kumar Vootla et. al., (2017) [26]. $40.4^{\circ}$ corresponding to $\left(\begin{array}{ll}0 & 0\end{array}\right)$ plane of chromium ( $\mathrm{Cr}$ ) hexagonal phase with the standard value (JCPDS file No. 89-2871). Similar results were observed by Nattakarn Poolphol et. al., (2017) [27].

XRD image of carbon nanotubes confirms the hexagonal structure according to JCPDS data (JCPDS file No. $41-1487$ ) at $26.1^{\circ}, 43.8^{\circ}$,

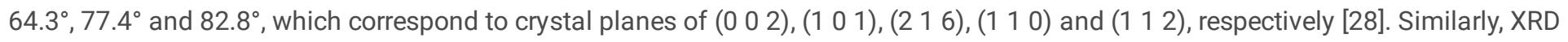
image of silicon nanoparticles confirms the cubic structure according to JCPDS data (JCPDS file No. 80-0018) at 28.6 $6^{\circ}, 47.6^{\circ}, 56.4^{\circ}$,

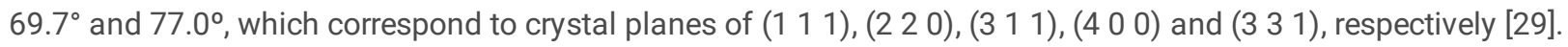

\subsubsection{Calculation of particle size}

Using Debye-Scherrer formula [30,31], the average particle size of the prepared composite materials were calculated and are summarized as shown in Table 3. It was observed that the particle size of AA 2024 was found to be $39.1 \mathrm{~nm}$, and the particle size of AA $2024+4 \%$ CNT $+2 \%$ Si was found to be $23.6 \mathrm{~nm}$. It is concluded that the average particle size decreases with an increase in carbon nanotubes and silicon nanoparticles.

Table 3 Average Particle Size for the Composites

\begin{tabular}{|lll|}
\hline S. No. & Composition (wt \%) & Particle size $(\mathrm{nm})$ \\
\hline 1 & AA 2024 & 39.1 \\
\hline 2 & PURE CNT & 15.6 \\
\hline 3 & PURE SILICON & 17.7 \\
\hline 4 & AA 2024 + 2\% CNT & 26.7 \\
\hline 5 & AA 2024 + 4\% CNT & 25.4 \\
\hline 6 & AA 2024 + 2\% Si & 27.7 \\
\hline 7 & AA 2024 + 4\% Si & 25.9 \\
\hline 8 & AA 2024 + 2\% CNT + 2\% Si & 27.6 \\
\hline 9 & AA 2024 + 2\% CNT + 4\% Si & 26.8 \\
\hline 10 & AA 2024 + 4\% CNT + 2\% Si & 23.6 \\
\hline 11 & AA 2024 + 4\% CNT + 4\% Si & 25.7 \\
\hline
\end{tabular}

\subsection{Dielectric Properties Analysis}

\subsubsection{Frequency dependency of dielectric constant and dielectric loss}

It is known that dielectric constant and also dielectric loss of material changes with frequency and also reinforcements. In view of this, a variation of dielectric constant and dielectric loss with an increase in frequency and reinforcements for the synthesized composites were studied and the results are pictorially represented as shown in Fig. 9 a-i \& 10 a-i respectively, and the calculated values are tabulated (Table 4).

The graph gives a clear signature of the compositional effect on the dielectric constant and dielectric loss of the materials. It is concluded from the results obtained that the dielectric constant and dielectric loss decreases smoothly with the addition of reinforcements and increase in frequency.

Table 4 Dielectric properties Calculation 


\begin{tabular}{|lll|}
\hline Composition & Dielectric Constant & Dielectric Loss \\
\hline AA 2024 & 0.652 & 0.641 \\
\hline AA 2024 + 2\% CNT & 0.256 & 0.313 \\
\hline AA 2024 + 4\% CNT & 0.084 & 0.010 \\
\hline AA 2024 + 2\% Si & 0.07 & 0.097 \\
\hline AA 2024 + 4\% Si & 0.111 & 0.026 \\
\hline AA 2024 + 2\% CNT + 2\% Si & 0.071 & 0.016 \\
\hline AA 2024 + 2\% CNT + 4\% Si & 0.046 & 0.027 \\
\hline AA 2024 + 4\% CNT + 2\% Si & 0.006 & 0.004 \\
\hline AA 2024 + 4\% CNT + 4\% Si & 0.037 & 0.010 \\
\hline
\end{tabular}

Generally, as frequency increases, the net polarization of the material drops as each polarisation mechanism ceases to contribute, and hence its dielectric constant goes down. This mechanism is observed in the present study. Results indicate that the interrelation dipoles have a reduced amount of time to orient themselves in the direction of the applied field $[14,32,33]$.

From the results obtained, AA $2024+4 \%$ CNT $+2 \%$ Si composites shows low dielectric constant and low dielectric loss. Dielectric materials with low-loss are widely employed in communication systems and also in quite a lot of electronic devices [34-37].

\subsubsection{Dissipation factor}

A determination of energy lost through the turnaround of electric polarization is called the dissipation factor. It measures the inefficiency of insulating material. Variations of dissipation factor with frequency and reinforcements for the prepared composites are depicted in Fig. 11 a-i. It can be seen from results that when the mixture of carbon nanotubes and silicon were added AA 2024, the dissipation factor decreases with an increase in frequency and reinforcements. Alternate results (for example, conductor-insulator systems) were observed for the rest of the samples. V. Singh et. al., shows similar results [32]. Out of all, AA $2024+4 \% \mathrm{CNT}+2 \% \mathrm{Si}$ composites shows better results.

\section{Conclusion}

AA 2024, AA 2024 + 2\% CNT, AA 2024 + 4\% CNT, AA 2024 + 2\% Si, AA 2024 + 4\% Si, AA 2024 + 2\% CNT + 2\% Si, AA $2024+2 \%$ CNT + $4 \% \mathrm{Si}, \mathrm{AA} 2024+4 \%$ CNT + 2\% Si and AA $2024+4 \%$ CNT + 4\% Si Composites were fabricated by stir casting procedure. Silicon nanoparticles were synthesized from bulk materials through high energy ball milling technique.

The following conclusions have been made:

- SEM micrograph for the prepared samples reveals that the reinforcement particles are distributed evenly throughout the specimen.

- EDX study discloses the identification of elements and their quantity. It was found that the quantity of aluminium was found to be 91.96\%. This confirms that aluminium is the major element in AA2024. EDX spectra shows that all the major components of AA2024, carbon nanotubes and silicon.

- The result of the XRD confirms the presence of various phases present in the composite materials. Crystal structure of various elements and particle size of the composites were also evaluated. For example, the diffraction peak $(2 \theta)$ observed at $38.6^{\circ}$ is corresponding to (1 111 ) plane of aluminium (Al) cubic phase which matches with the standard value (JCPDS file No. 04-0787). Results obtained through EDX are in accordance with the results of XRD analysis.

- In accordance with the results of the Hioki 3532-50 LCR Hi-Tester, the dielectric constant, dielectric loss and dissipation factor decreases with an increase in reinforcements and frequency, which has been attributed to interrelation dipoles. The test results obtained indicate that the dielectric properties offered by AA $2024+4 \%$ CNT $+2 \% \mathrm{Si}$ composites were superior to those of other composites. 


\section{References}

[1] R. Casati, M. Vedani, A Review Metals. 4, 65-83 (2014)

[2] N.V. Murthy, A. Prasad Reddy, N. Selvaraj, C.S.P. Rao, IOP Conf. Ser.: Mater. Sci. Eng.149, 012106 (2016)

[3] S. Ghanaraja, S. Ray, S.K. Nath, Mater Today. 2, 3656-3665 (2015)

[4] O. Aranke, C. Gandhi, N. Dixit, P. Kuppan, Mater Today 5, 7748-7757 (2018)

[5] M. Rajendran, A.R. Suresh, Mater Today 5, 8314-8320 (2018)

[6] O. Carvalho, G. Miranda, D. Soares, F.S. Silva, Ciencia \& Tech dos Mater 25, 75-78 (2013)

[7] M. Qian, X. Zhang, J. Li, X. Gao, Mater Chem Phys 226, 344-349 (2019)

[8] D.K. Lim, T. Shibayanagi, A.P. Larlic, Mater Sci Eng A 507, 194-199 (2009)

[9] K.E. Petersen, IEEE 70, 420-457 (1982)

[10] OS. Yakovenko, LY. Matzui, LL. Vovchenko, Inorg Mater. 52, 1198-1203 (2016)

[11] S. Soltani, R. Azari Khosroshahi, R. Taherzadeh Mousavian, Rare Met. 36, 581-590 (2017)

[12] A. Loni, Springer 6, 1-9 (2014)

[13] M. Vadivel, R. RameshBabu, K. Sethuraman, K. Ramamurthi, M. Arivanandhan, J. Magn. Magnet.

Mater. $\mathbf{3 6 2 , 1 2 2 - 1 2 9}$

(2014)

[14] S. Akhter, DP. Paul, MA. Hakim, DK. Saha, HN. Das, Mat Res 21, 4 (2018)

[15] Lau Yien Jun, Lau Sie Yon, N.M. Mubarak, Mater Sci Eng. 495, 012057 (2019)

[16] Bahar Demirel, Kürşat E. Alyama, Civil Struct Eng. 21, 181-197 (2018)

[17] Giancarlo Richard Salazar-Banda, Katlin Ivon Barrios Eguiluz, Mater Res 16, 1315-1324 (2013)

[18] Sourabh Biswas, Habib Alavi S, Sandip P Harimkar, J Compos Sci. 1, 13 (2017)

[19] M. Senthil Kumar, R.V. Mangalaraja, R. Senthil Kumar, L. Natrayan, Iran J Mater Sci Eng 16, 2 (2019)

[20] T. Theivasanthi, M. Alagar, Arch Phys Res 1, 112-117 (2010)

[21] Alain Manceau, Anatolii I Gorshkov, Victor A Drits, American Mineralogist. 77, $\quad$ 1144- 1157 (1992)

[22] Sumiaki Nakano, Shin-ichi Yamaura, Akiko Kitano, Masugu Sato, Mater Trans 45, 3232-3234 (2004)

[23] Yoshiaki Hirano, Yuka Kasai, Kunimasa Sagata, Bull Chem Soc Jpn 89, 9 (2016)

[24] Dang Le Tri Nguyen, Michael Shincheon Jee, Da Hye Won, Hyejin Jung, ACS Sustainable Chem Eng 5, 12 (2017)

[25] Chia-Hao Lu, Tzu-Yang Chao, Ying-Feng Chiu, Shuo-Yen Tseng, Nanoscale Res Lett 9, 178 (2014)

[26] Ashok Kumar Vootla, Pulla Sammaiah, IOSR J Eng. 7, 9 (2017)

[27] Nattakarn Poolphol, Tatchakorn Sakkaew, Keerati Kachin et al, Mater Today 4, 6358-6364 (2017)

[28] G.Y. Cui, C.Y. Wang, G.Q. Xiang, B. Zhou, Mater Sci Eng 292, 012034 (2017)

[29] Dong-Won Jung, Kwang-Hyun Kim, JungKyoo Lee, J Nanosci Nanotechnol 13, 7855-7859 (2013) 
C.C. Chauhan, R.B. Jotania, Solid State Phenomena 209, 74-77 (2014)

[32] V. Singh, AR. Kulkarni, TR. Rama Mohan, J. Appl. Polym. Sci. 90, 3602-3608 (2003)

[33] Ch. Mamatha, M. Krishnaiah, CS. Prakash, KG. Rewatkar, Procedia Materials Science. 5, 780-786 (2014)

[34] He Seung Lee, Albert. S. Lee, Kyung-Youl Baek, Seung Sang Hwang, Intechopen. doi: 10.5772/51499 (2012)

[35] MT. Sebastian, Elsevier. 525-530 (2008)

[36] Saira Riaz, Sajid-ur-Rehman, Mymona Abutalib, Shahzad Naseem, Mater. 45, 5185-5197 (2016)

[37] S. Anand, V. Maria Vinosel, M. Asisi Jenifer, S. Pauline, Int. Res. J. Eng. Technol. 04, 358-362 (2017)

\section{Tables}

Table 1

\begin{tabular}{|c|c|c|c|c|c|c|c|c|c|c|c|}
\hline Element & $\begin{array}{c}\mathrm{AA} 2024 \\
(\%)\end{array}$ & $\begin{array}{l}\text { CNT } \\
(\%)\end{array}$ & $\begin{array}{l}\mathrm{Si} \\
(\%)\end{array}$ & $\begin{array}{c}\mathrm{AA} 2024 \\
+ \\
2 \% \mathrm{CNT} \\
\end{array}$ & $\begin{array}{c}\mathrm{AA} 2024 \\
+ \\
4 \% \mathrm{CNT} \\
\end{array}$ & $\begin{array}{c}\mathrm{AA} 2024 \\
+ \\
2 \% \mathrm{Si} \\
\end{array}$ & $\begin{array}{c}\mathrm{AA} 2024 \\
+ \\
4 \% \mathrm{Si} \\
\end{array}$ & $\begin{array}{c}\mathrm{AA} 2024 \\
+2 \% \mathrm{CNT} \\
+2 \% \mathrm{Si} \\
\end{array}$ & $\begin{array}{c}\mathrm{AA} 2024 \\
+2 \% \mathrm{CNT} \\
+4 \% \mathrm{Si} \\
\end{array}$ & $\begin{array}{c}\mathrm{AA} 2024 \\
+4 \% \mathrm{CNT} \\
+2 \% \mathrm{Si} \\
\end{array}$ & $\begin{array}{c}\text { AA2 } 024 \\
+4 \% \mathrm{CNT} \\
+4 \% \mathrm{Si} \\
\end{array}$ \\
\hline $\mathrm{Al}$ & 91.96 & 1.72 & - & 88.66 & 86.74 & 89.25 & 86.82 & 86.14 & 84.85 & 83.72 & 81.80 \\
\hline C & - & 75.40 & - & 1.94 & 3.95 & - & - & 1.96 & 1.98 & 3.98 & 3.97 \\
\hline $\mathrm{Si}$ & 0.49 & - & 73.19 & 0.47 & 0.41 & 2.45 & 4.47 & 2.41 & 4.38 & 2.43 & 4.32 \\
\hline $\mathrm{O}$ & - & 22.88 & 26.81 & 2.87 & 2.13 & 2.08 & 2.09 & 2.14 & 2.73 & 1.58 & 2.41 \\
\hline $\mathrm{Mg}$ & 1.64 & - & - & 1.22 & 1.18 & 1.25 & 1.27 & 1.15 & 1.23 & 1.27 & 1.18 \\
\hline $\mathrm{Mn}$ & 0.68 & - & - & 0.51 & 0.47 & 0.46 & 0.48 & 0.51 & 0.45 & 0.47 & 0.49 \\
\hline $\mathrm{Fe}$ & 0.43 & - & - & 0.67 & 1.46 & 0.92 & 0.89 & 1.98 & 1.14 & 2.07 & 2.18 \\
\hline $\mathrm{Cu}$ & 4.5 & - & - & 3.58 & 3.58 & 3.59 & 3.98 & 3.43 & 3.24 & 4.48 & 3.65 \\
\hline $\mathrm{Cr}$ & 0.09 & - & - & 0.08 & 0.08 & - & - & 0.08 & - & - & - \\
\hline $\mathrm{Zn}$ & 0.21 & - & - & - & - & - & - & 0.20 & - & - & - \\
\hline
\end{tabular}

Table 2

\begin{tabular}{c|c|c|c|c|c|c|}
\hline 5. No & Element & 2 Theta(deg) & Hkl & Cell Parameters & Structure & JCPDS No \\
\hline 1 & $\mathrm{Al}$ & 38.6 & 111 & $\mathrm{a}=\mathrm{b}=\mathrm{c}=4.049$ & Cubic & $04-0787$ \\
\hline 2 & $\mathrm{Cu}$ & 44.6 & 111 & $\mathrm{a}=\mathrm{b}=\mathrm{c}=3.615$ & Cubic & $04-0836$ \\
\hline 3 & $\mathrm{Mn}$ & 64.8 & 331 & $\mathrm{a}=\mathrm{b}=\mathrm{c}=6.30$ & Cubic & $89-4086$ \\
\hline 4 & $\mathrm{Mg}$ & 78.4 & 202 & $\mathrm{a}=\mathrm{b}=3.208, \mathrm{c}=5.209$ & Hexagonal & $89-5003$ \\
\hline 5 & $\mathrm{Fe}$ & 82.6 & 211 & $\mathrm{a}=\mathrm{b}=\mathrm{c}=2.866$ & Cubic & $87-0721$ \\
\hline 6 & $\mathrm{Zn}$ & 35.5 & 002 & $\mathrm{a}=\mathrm{b}=2.665, \mathrm{c}=4.947$ & Hexagonal & $87-0713$ \\
\hline 7 & $\mathrm{Cr}$ & 40.6 & 002 & $\mathrm{a}=\mathrm{b}=2.722, \mathrm{c}=4.434$ & Hexagonal & $89-2871$ \\
\hline 8 & $\mathrm{Si}$ & $28.6,47.6$ & 111,220 & $\mathrm{a}=\mathrm{b}=\mathrm{c}=5.392$ & Cubic & $80-0018$ \\
\hline 9 & $\mathrm{CNT}$ & $26.1,43.8$ & 002,101 & $\mathrm{a}=\mathrm{b}=2.470, \mathrm{c}=6.724$ & Hexagonal & $41-1487$ \\
\hline
\end{tabular}

Table 3 


\begin{tabular}{|c|c|c|}
\hline S. No. & Composition (wt \%) & Particle size (nm) \\
\hline 1 & AA 2024 & 39.1 \\
\hline 2 & PURE CNT & 15.6 \\
\hline 3 & PURE SILICON & 17.7 \\
\hline 4 & AA $2024+2 \%$ CNT & 26.7 \\
\hline 5 & AA $2024+4 \%$ CNT & 25.4 \\
\hline 6 & AA $2024+2 \%$ Si & 27.7 \\
\hline 7 & AA $2024+4 \%$ Si & 25.9 \\
\hline 8 & AA $2024+2 \%$ CNT $+2 \%$ Si & 27.6 \\
\hline 9 & AA $2024+2 \%$ CNT $+4 \%$ Si & 26.8 \\
\hline 10 & AA $2024+4 \%$ CNT $+2 \%$ Si & 23.6 \\
\hline 11 & AA $2024+4 \%$ CNT $+4 \%$ Si & 25.7 \\
\hline
\end{tabular}

Table 4

\begin{tabular}{|c|c|c|}
\hline Composition & Dielectric Constant & Dielectric Loss \\
\hline AA 2024 & 0.652 & 0.641 \\
\hline AA $2024+2 \%$ CNT & 0.256 & 0.313 \\
\hline AA $2024+4 \%$ CNT & 0.084 & 0.010 \\
\hline AA $2024+2 \% \mathrm{Si}$ & 0.07 & 0.097 \\
\hline AA $2024+4 \% \mathrm{Si}$ & 0.111 & 0.026 \\
\hline$\overline{A 2024+2 \% \mathrm{CNT}+2 \% \mathrm{Si}}$ & 0.071 & 0.016 \\
\hline A2024+2\% CNT + 4\% Si & 0.046 & 0.027 \\
\hline$\overline{A 2024+4 \% \mathrm{CNT}+2 \% \mathrm{Si}}$ & 0.006 & 0.004 \\
\hline A $2024+4 \%$ CNT $+4 \%$ Si & 0.037 & 0.010 \\
\hline
\end{tabular}

\section{Figures}

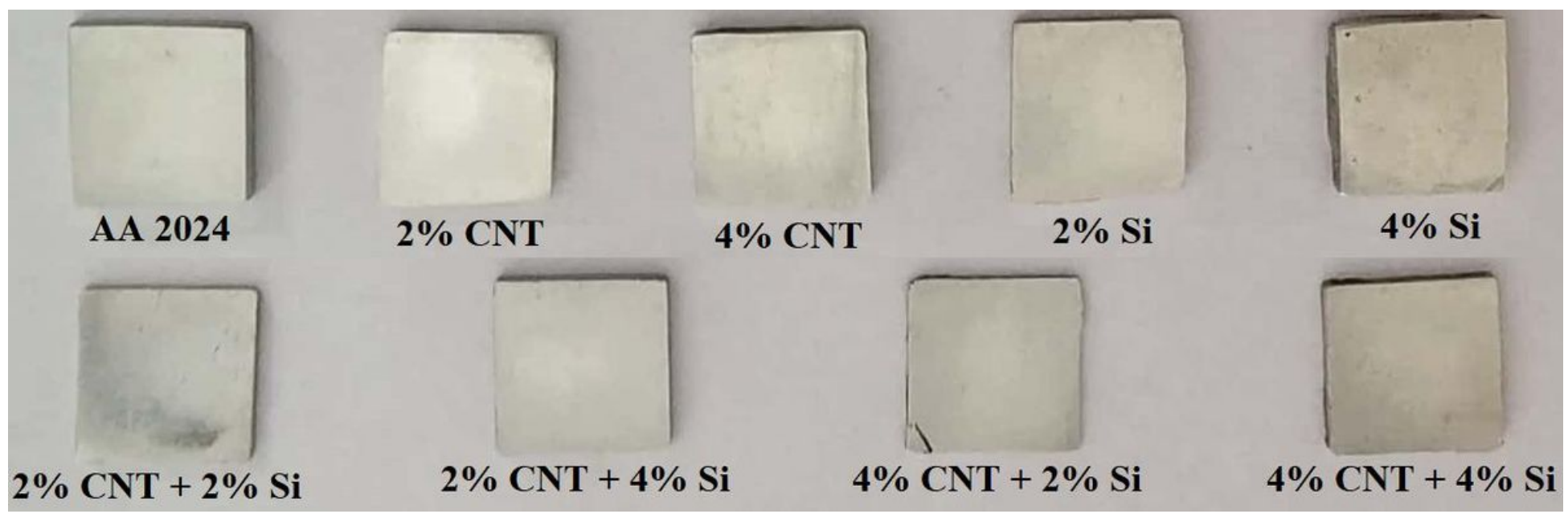

\section{Figure 1}

Samples used for SEM and EDX studies 


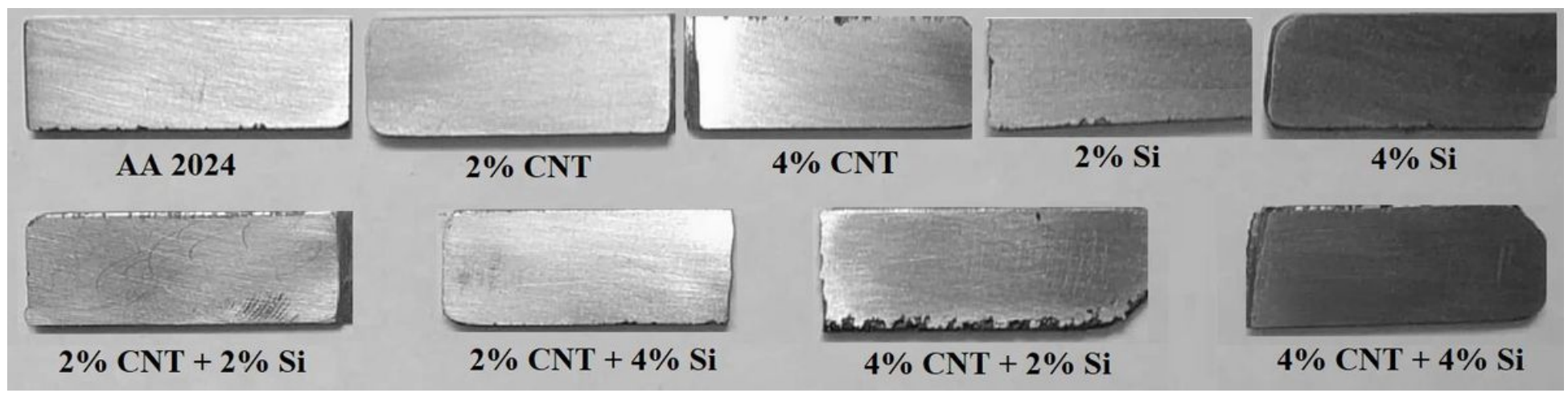

Figure 2

Samples used for XRD studies

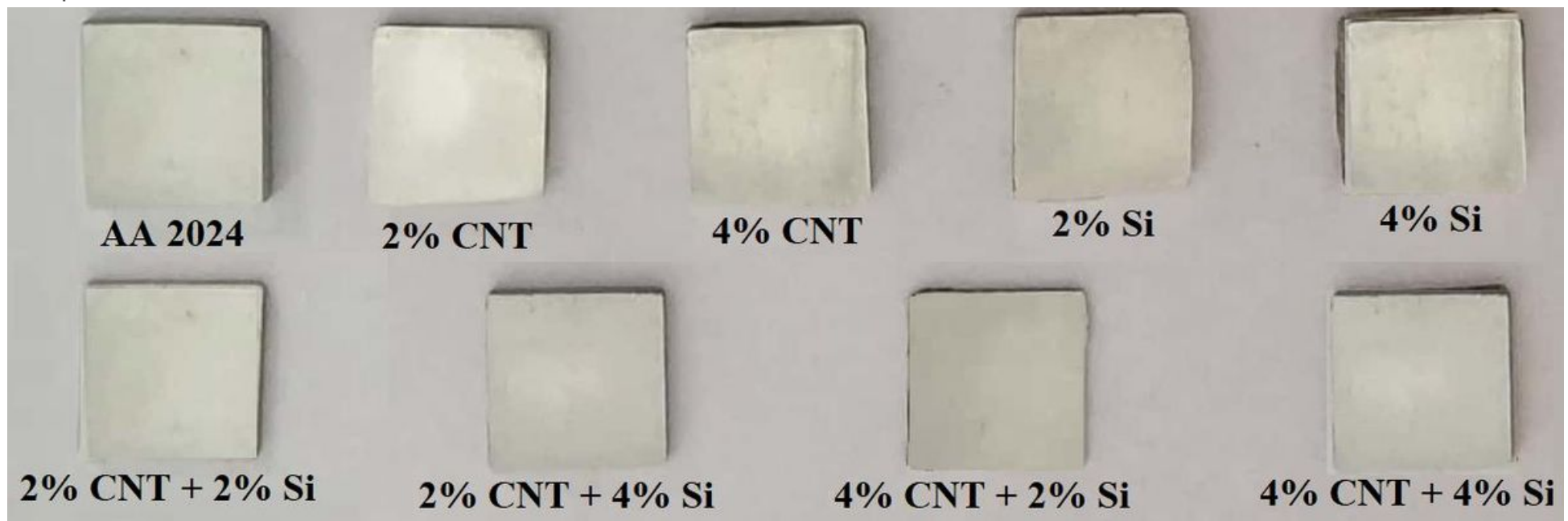

Figure 3

Samples used for Dielectric Studies 


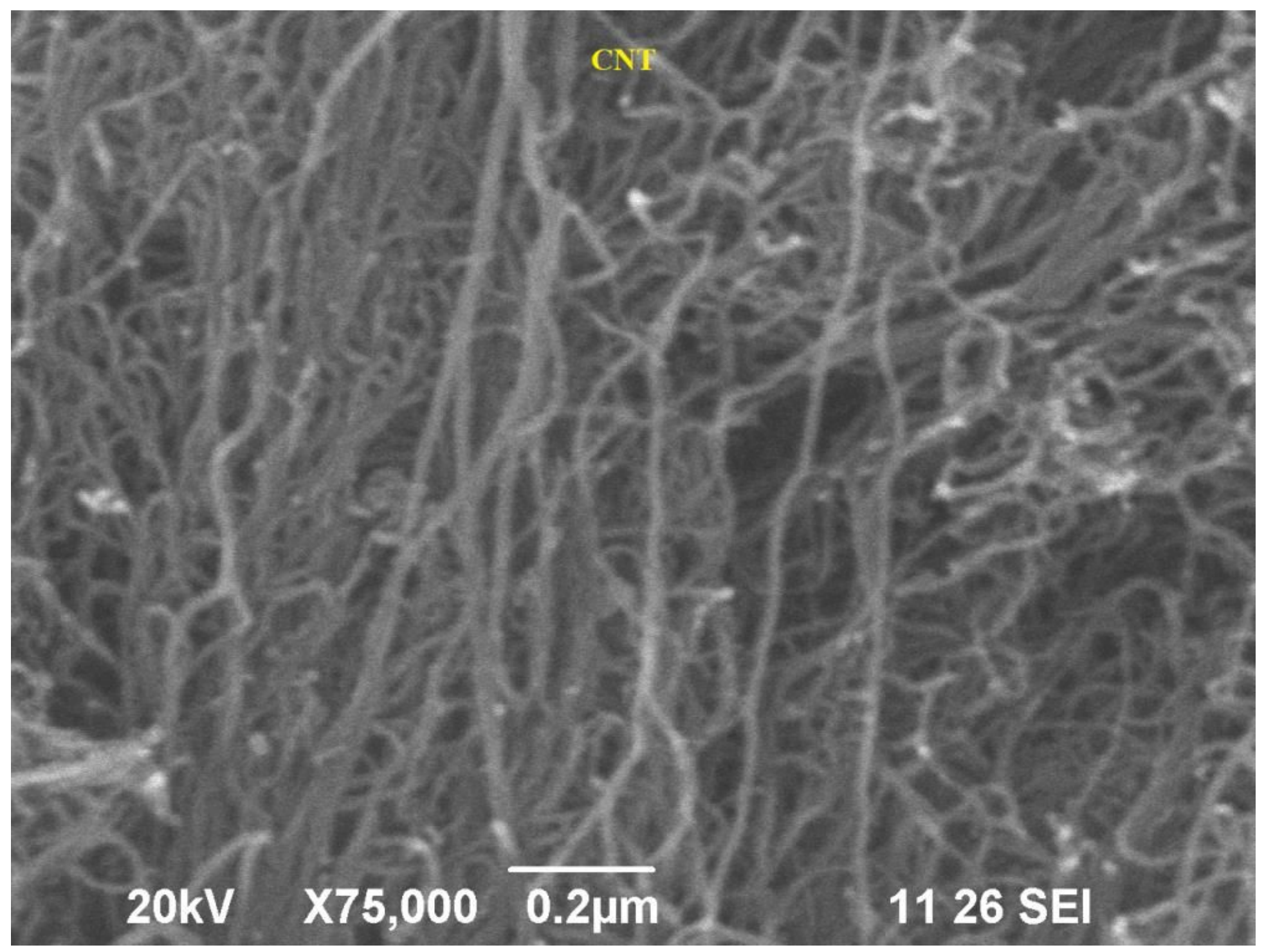

\section{Figure 4}

SEM image of Carbon Nanotubes 


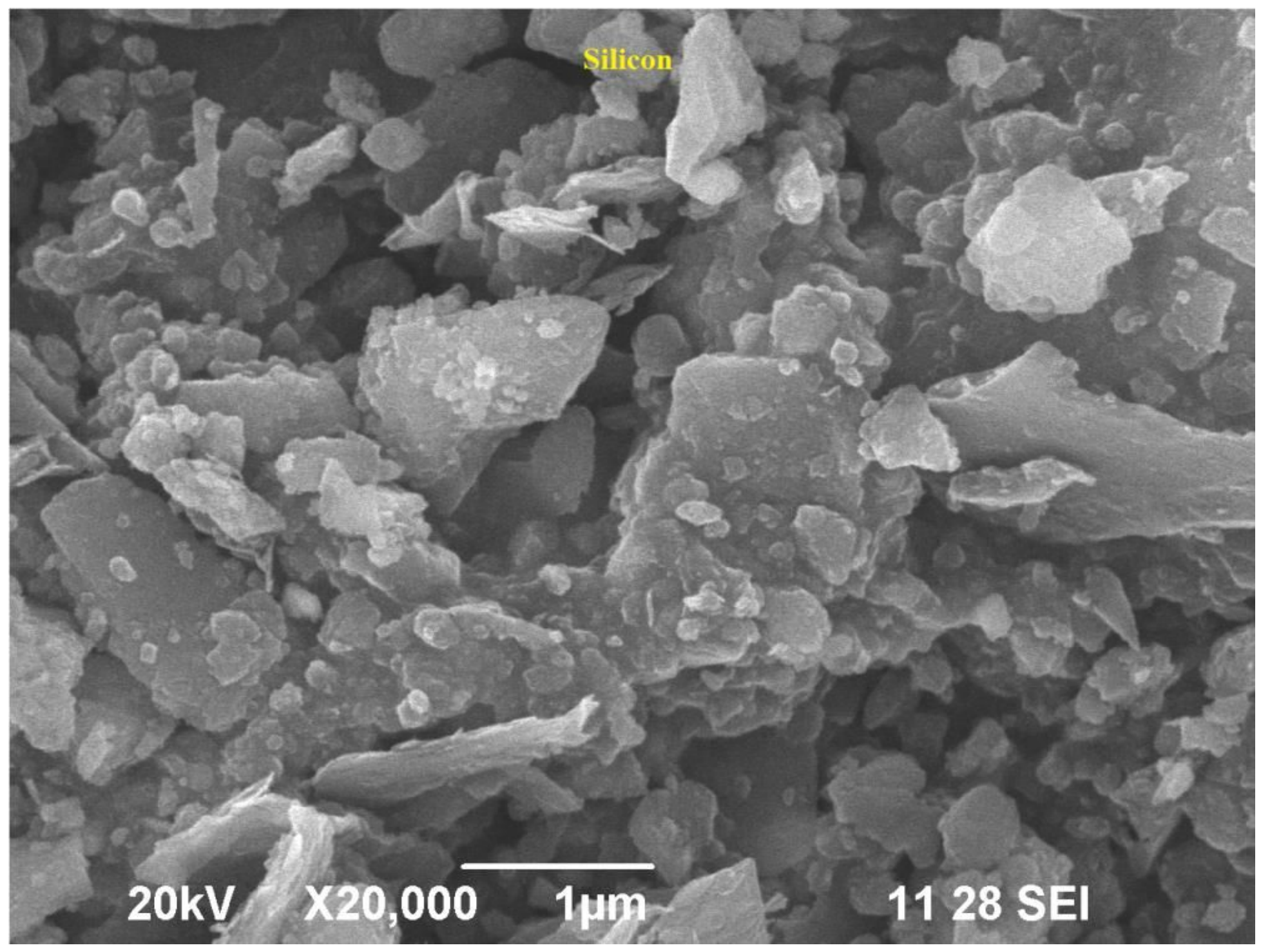

\section{Figure 5}

SEM image of Silicon 


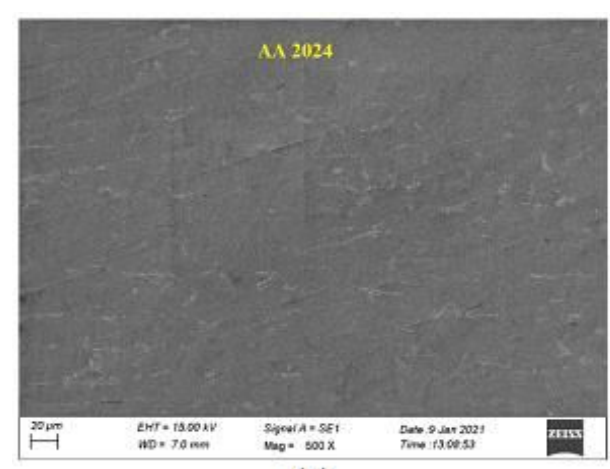

(a)

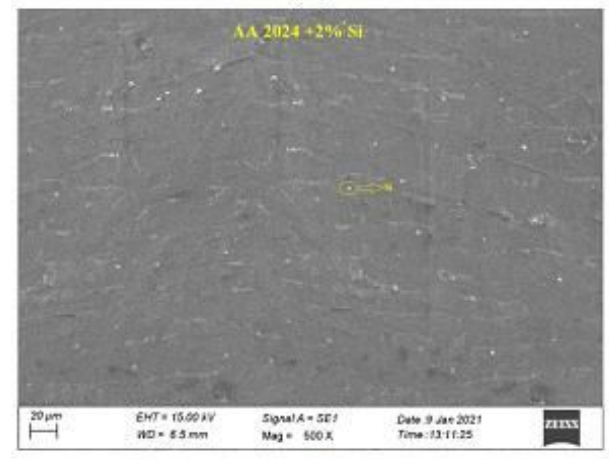

(d)

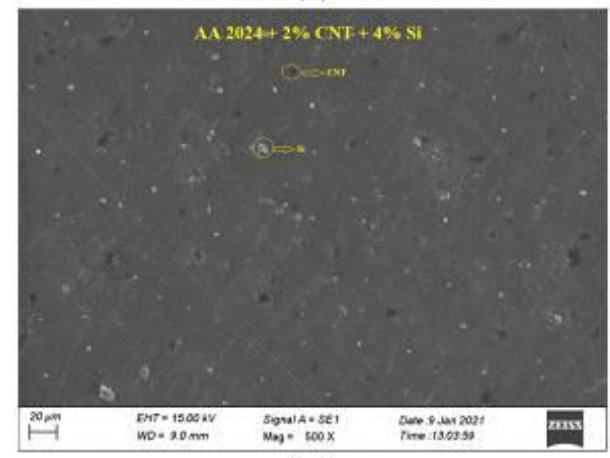

(g)

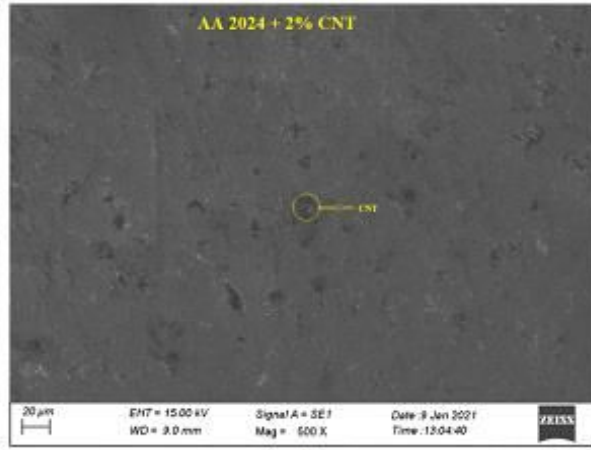

(b)

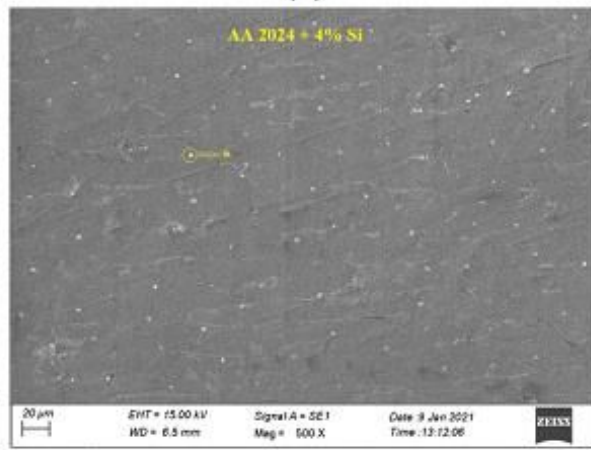

(e)

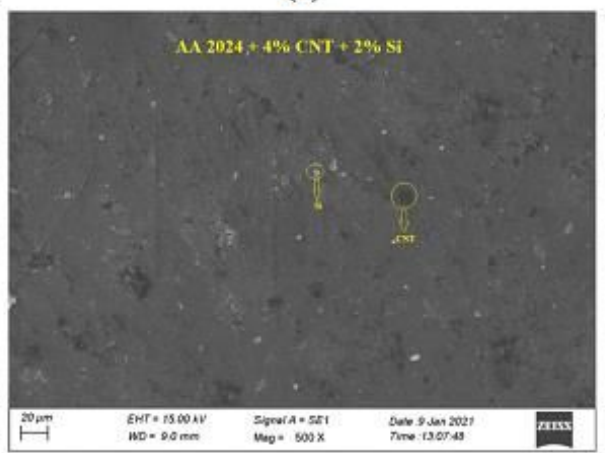

(h)

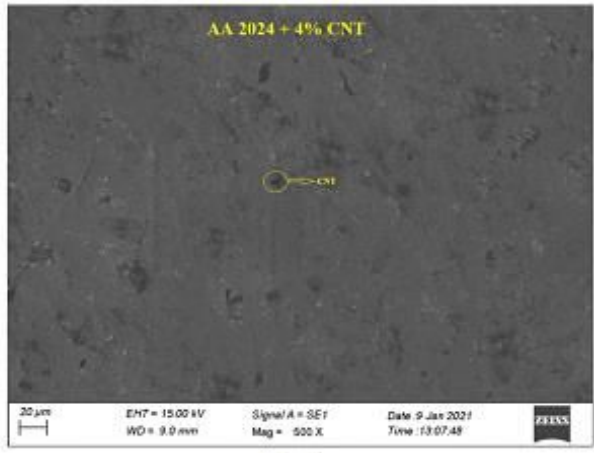

(c)

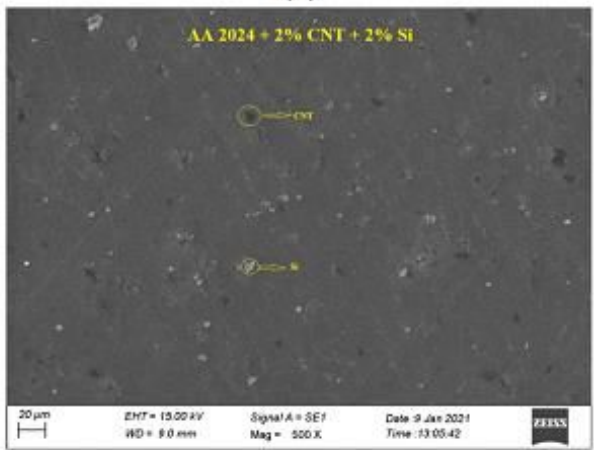

(f)

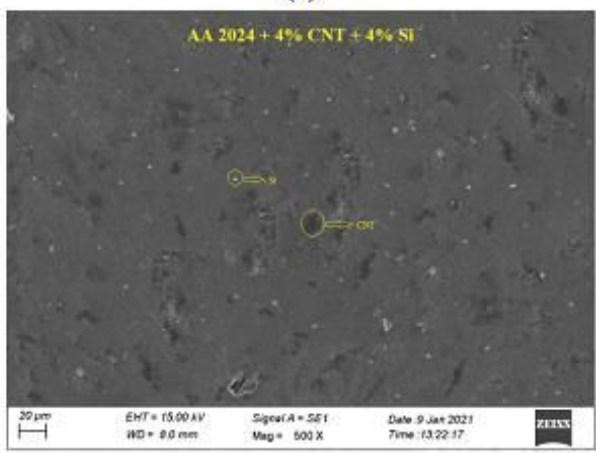

(i)

Figure 6

SEM image of AA 2024 HMMCs 


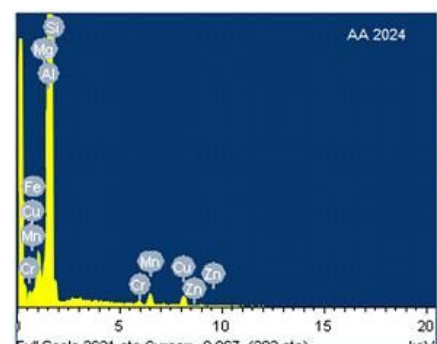

(a)

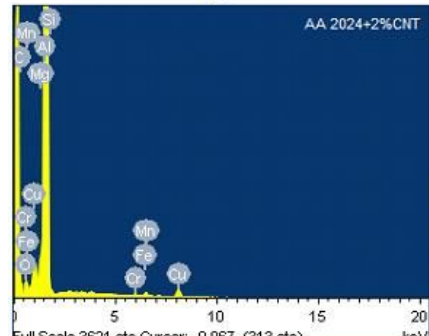

(d)

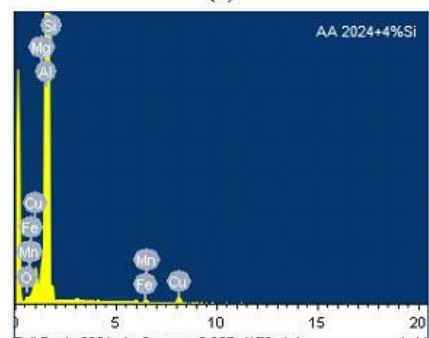

(g)
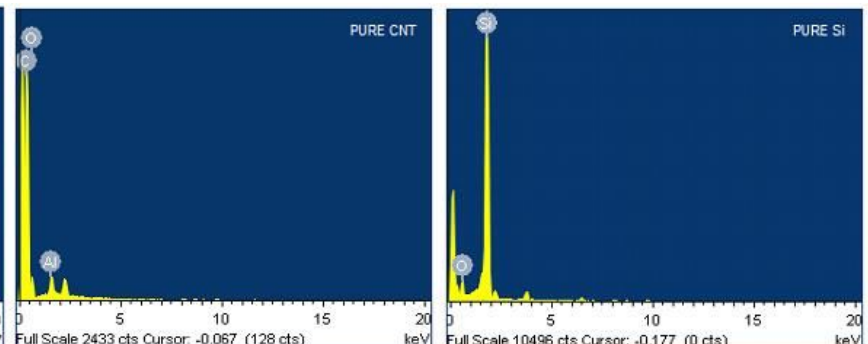

(b)

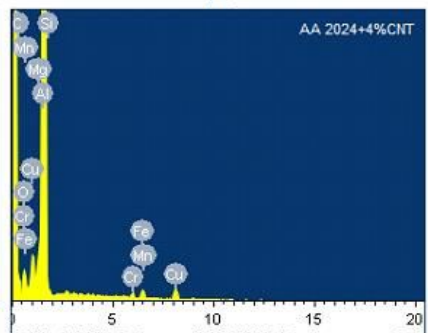

(c)

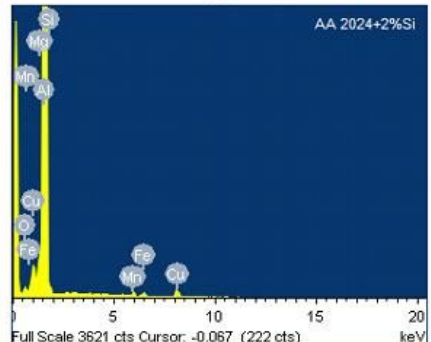

(e)

(f)
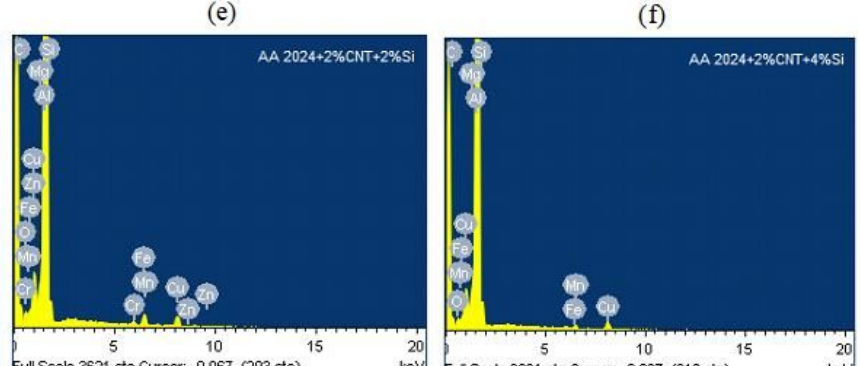

(h)

(i)
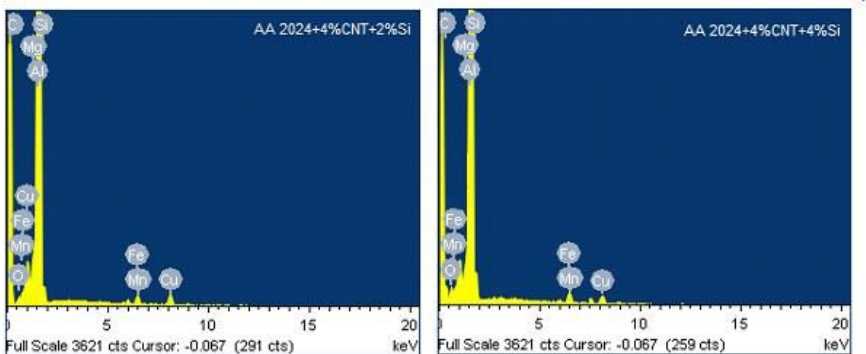

(j)

(k)

Figure 7

EDX spectra of AA 2024 HMMCs 


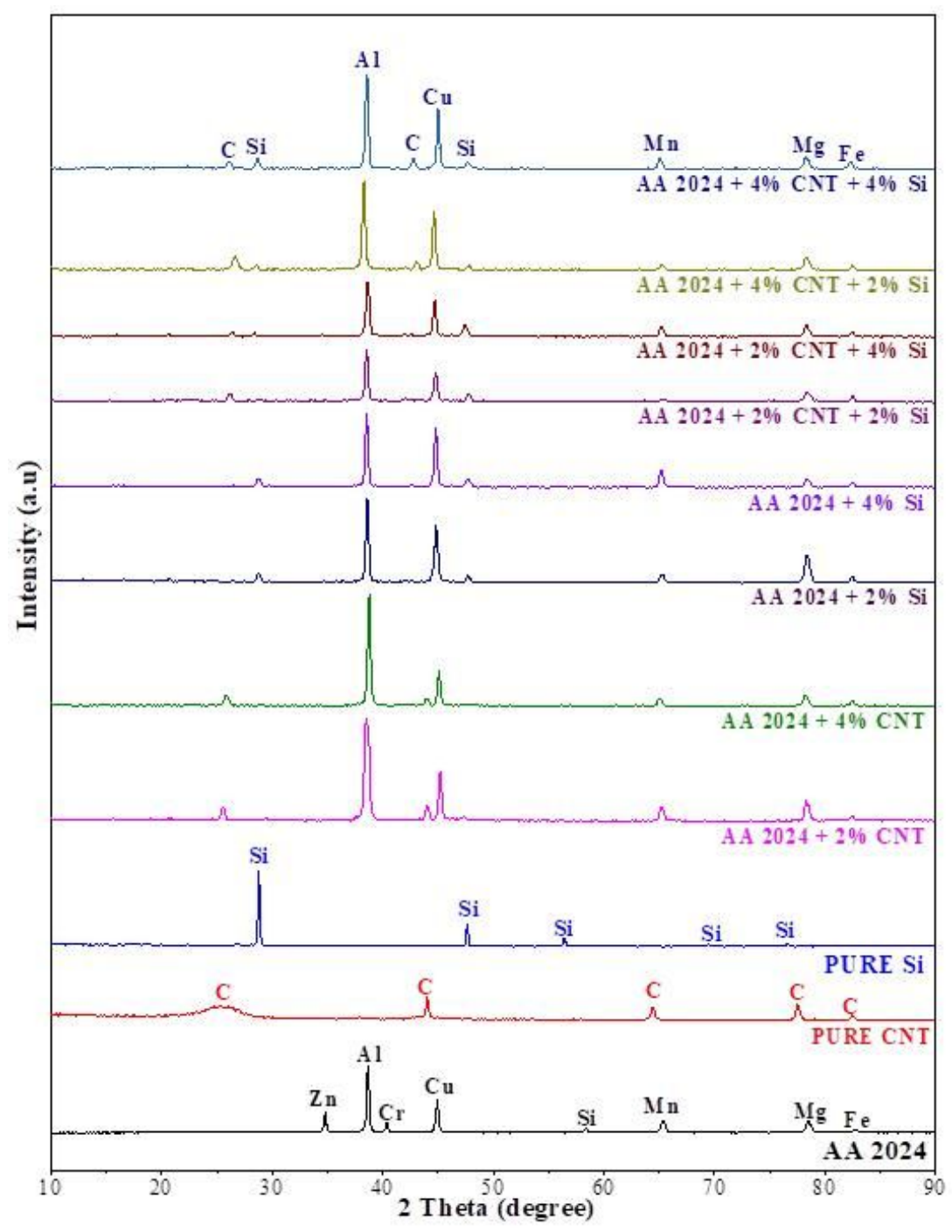

\section{Figure 8}

X-ray diffraction pattern of AA 2024 HMMCs 


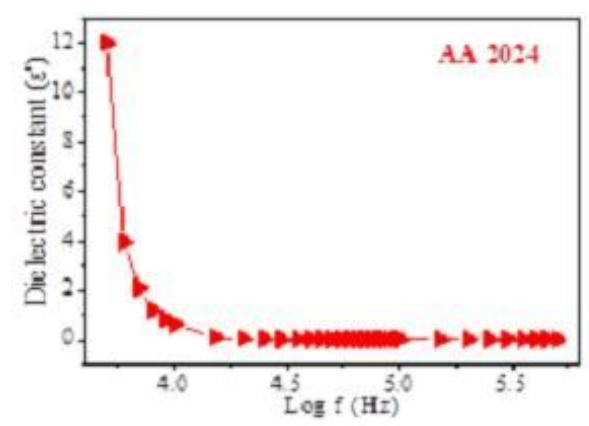

(a)

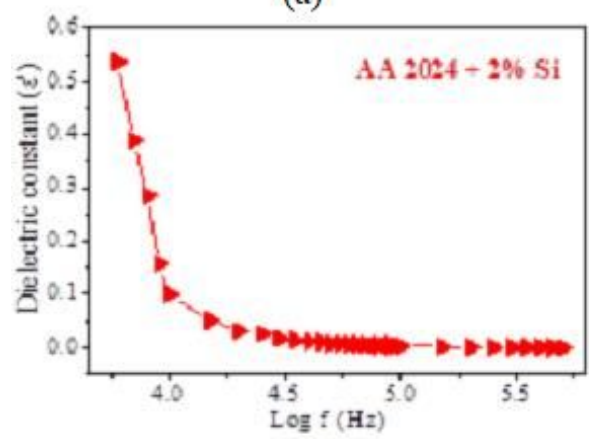

(d)

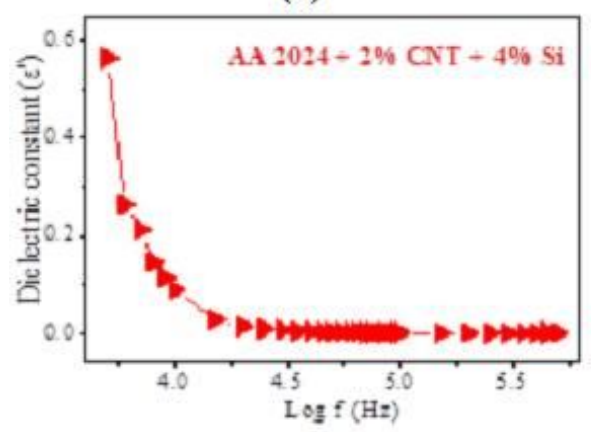

(g)

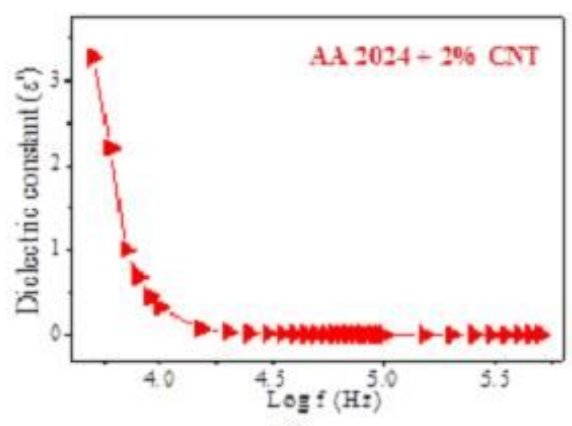

(b)

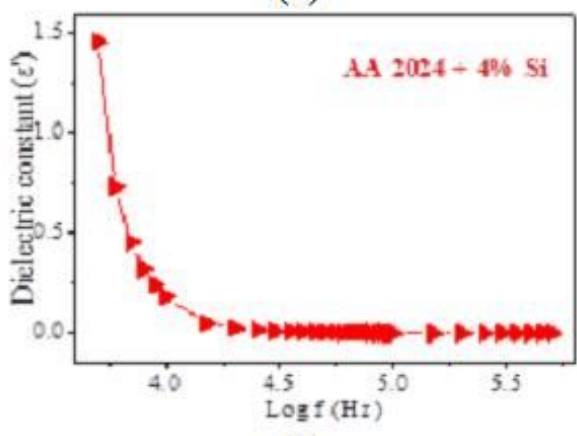

(e)

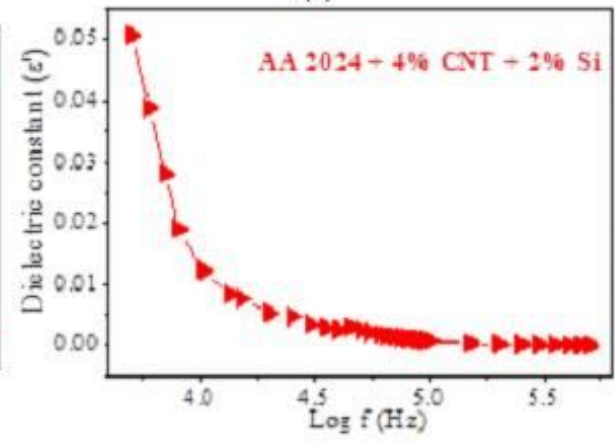

(h)

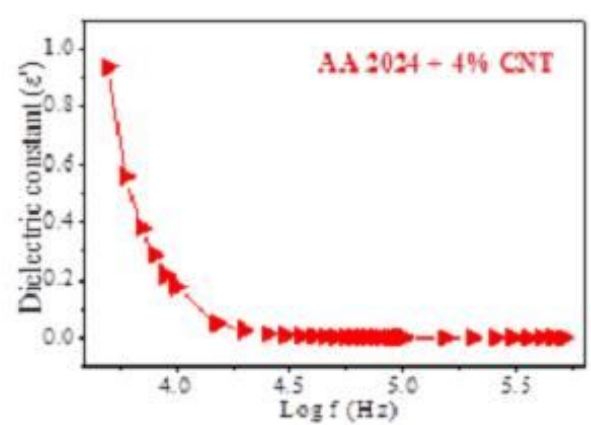

(c)

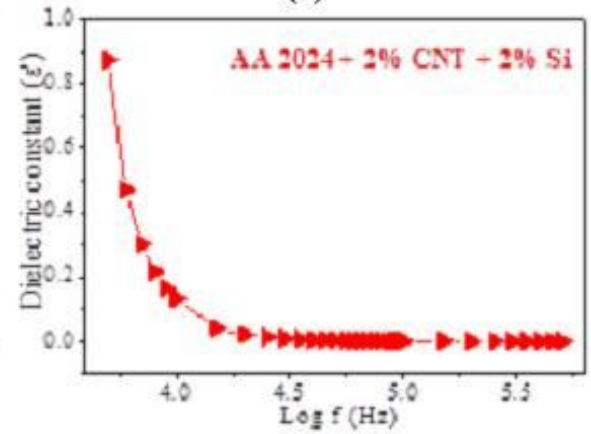

(f)

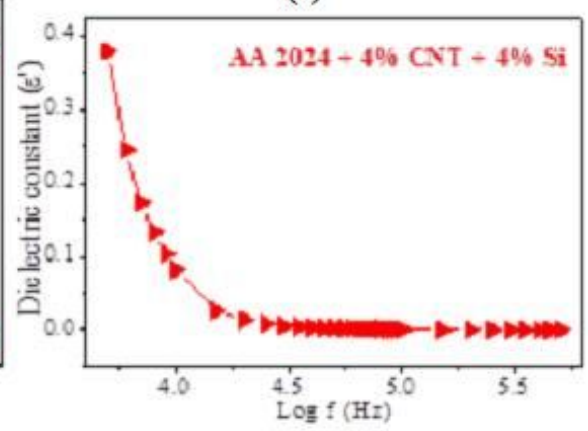

(i)

Figure 9

Variation of dielectric constant with frequency 


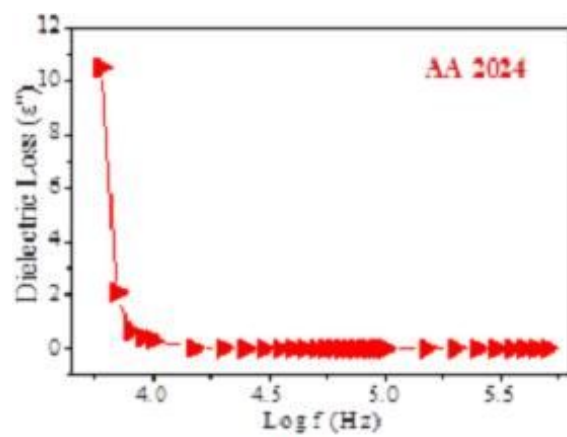

(a)

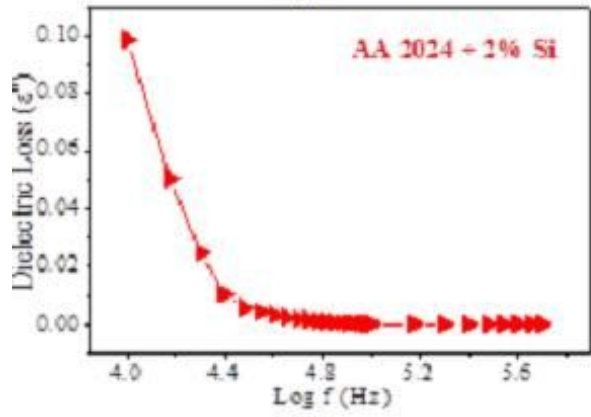

(d)

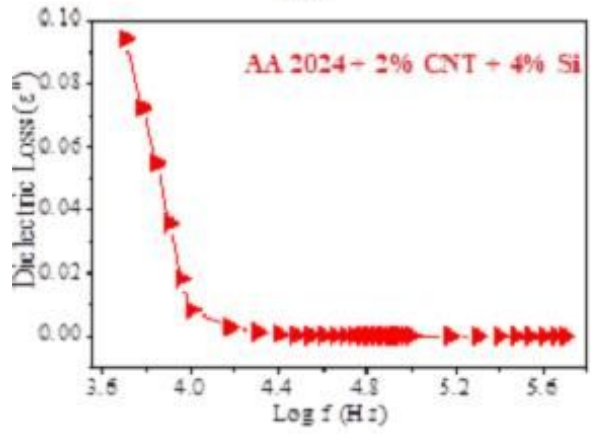

(g)

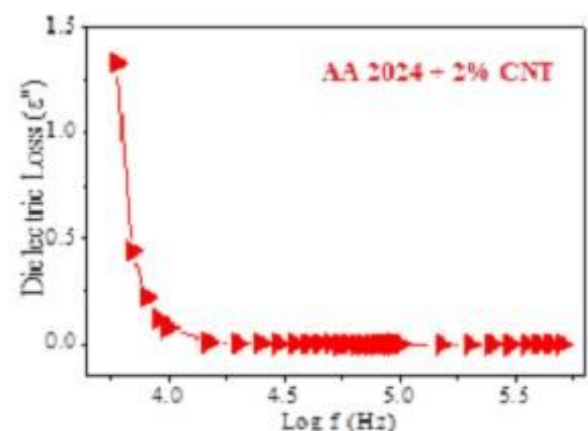

(b)

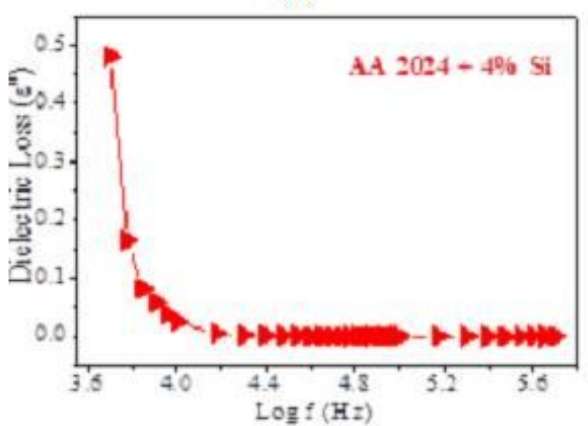

(e)

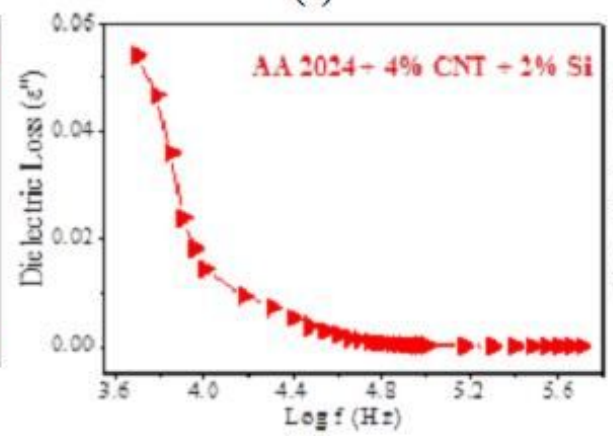

(h)

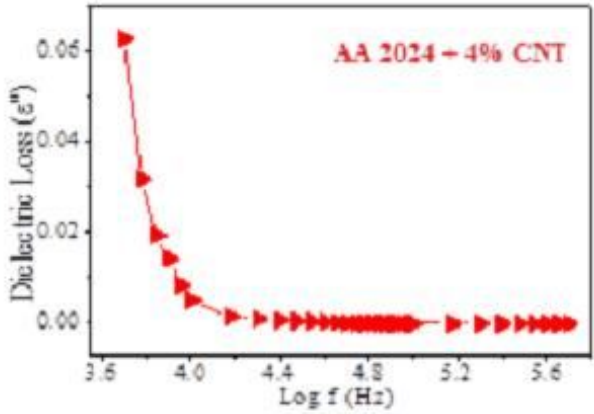

(c)

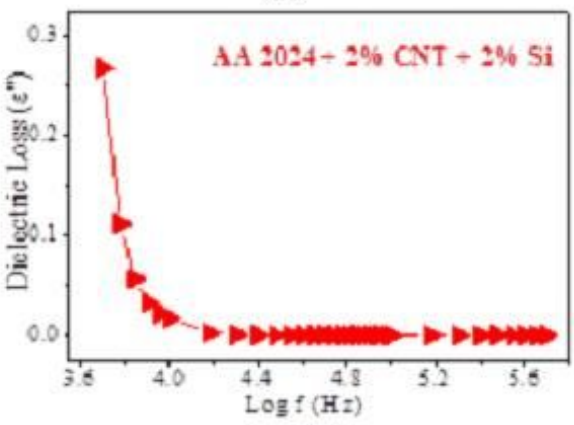

(f)

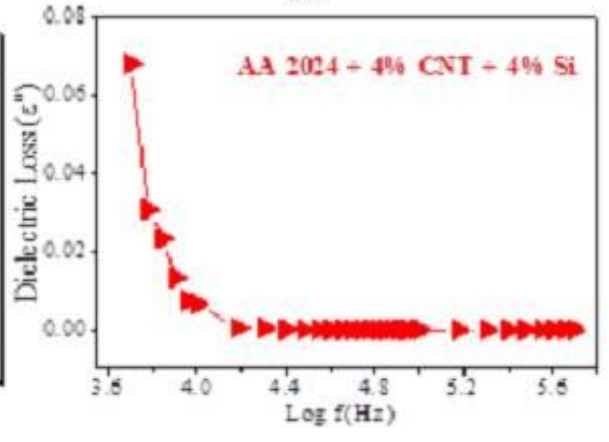

(i)

Figure 10

Variation of dielectric loss with frequency 


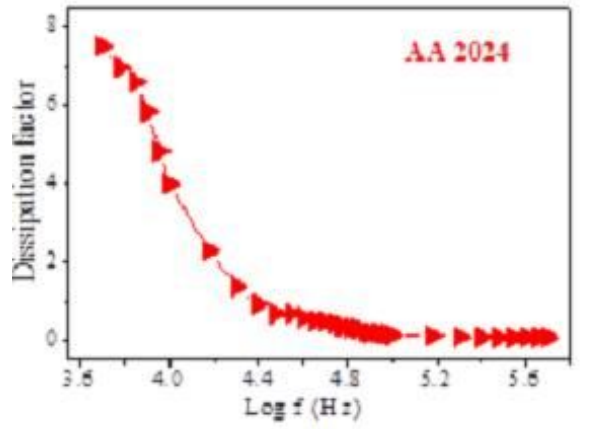

(a)

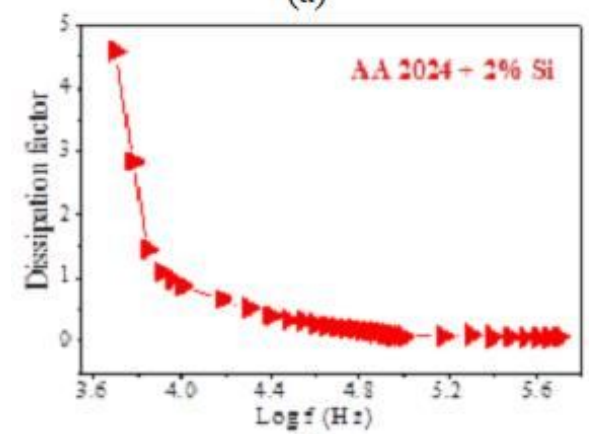

(d)

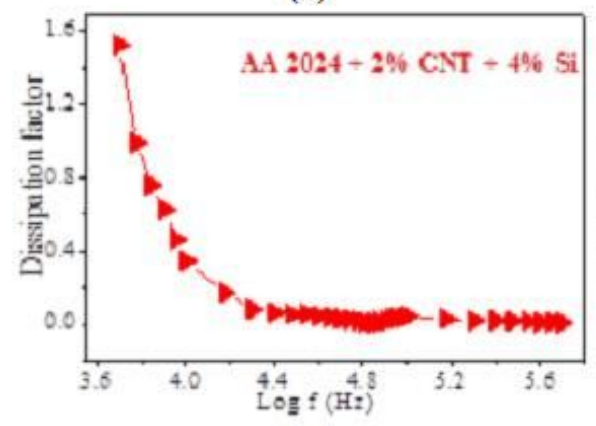

(g)

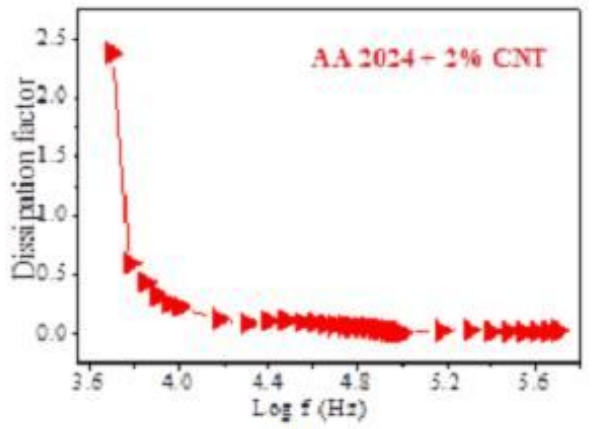

(b)

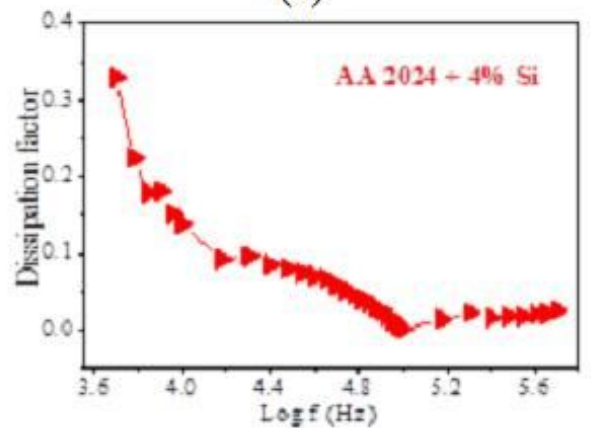

(e)

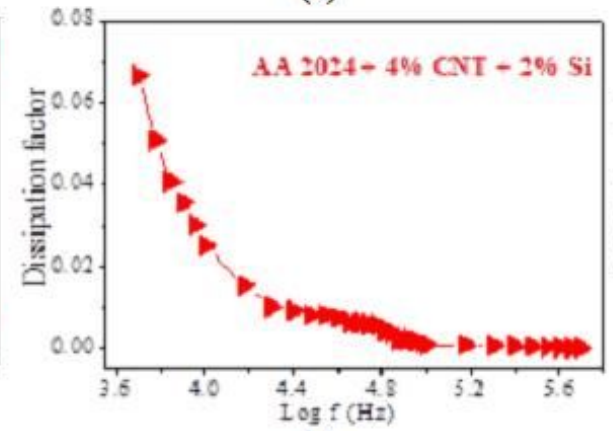

(h)

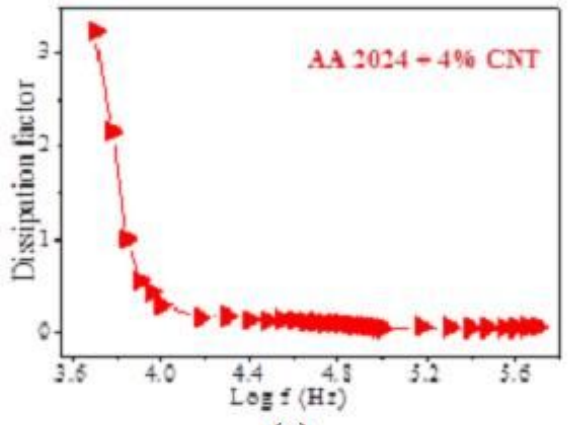

(c)

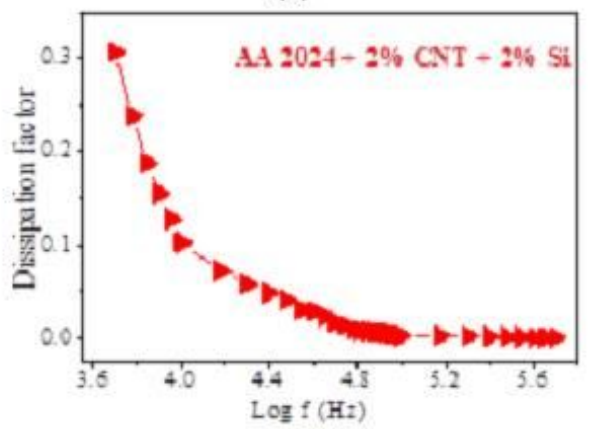

(f)

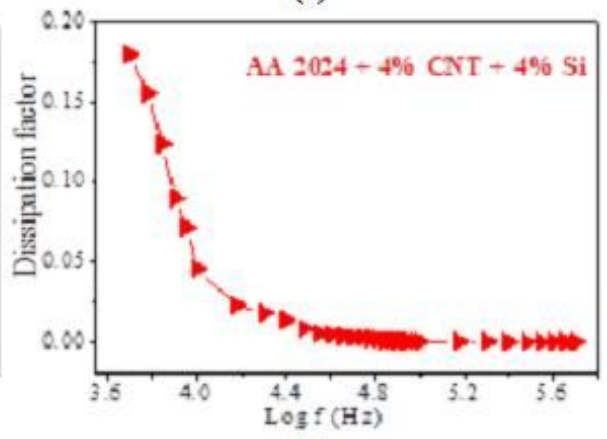

(i)

Figure 11

Variation of dissipation factor with frequency 